\title{
Gregorio Sánchez Gómez, novelista chocoano ${ }^{72}$
}

\author{
Jairo Henry Arroyo Reina
}

Recibido: 7 de Marzo 2011. Aprobado: 23 de Abril de 2011

\begin{abstract}
Resumen
Este ensayo presenta al escritor Gregorio Sánchez Gómez y a su obra como indispensables en el panorama literario, dada su valía para situar histórica, geográfica y simbólicamente zonas del pacífico sur y de la ciudad Cali representativas en la construcción del país, dados sus contenidos con alta denuncia social, política, anclados a los procesos de modernización y modernidad cultural.
\end{abstract}

Palabras clave: Gregorio Sánchez Gómez; Negredumbre; Novela colombiana; Novela Afrocolombiana; El relator.

\begin{abstract}
This essay presents the writer Gregorio Sánchez Gómez and his work as indispensable in the literary scene, given his value to locate historically, geographically and symbolically South Pacific areas and the city Cali representative in building the country, given its content with high complaint social, political, anchored to the processes of modernization and cultural modernity.
\end{abstract}

Keywords: Gregorio Sánchez Gómez; Black communities; Colombian novel; Afrocolombian novel; El relator.

Gregorio Sánchez Gómez escribió aproximadamente 20 libros, 16 de ellos en vida, 11 en la ciudad de Cali, de los cuales 8 fueron novelas. La bruja de las minas fue la décima cuarta novela de su vida, escrita hace setenta y dos años, en 1938. En este libro de XX capítulos, provisto de un índice de obras publicadas y de obras para publicar, se expresaron opiniones sobre Gregorio Sánchez por parte de autores como el crítico ecuatoriano Nicolás Jiménez y el Chileno Mariano Latorre.

Después de trasegar por editores y editoriales de la capital algunos de ellos libre pensadores y liberales como Luis Enrique Osorio, Juan Casis, Arturo zapata, y de publicar sus libros en los linotipos de los periódicos locales liberales y conservadores como Relator y Correo del Cauca, Gregorio Sánchez logró que Virgilio González R., editor del periódico El liberal de

\footnotetext{
${ }^{72}$ Artículo derivado del proyecto de investigación Biblioteca Afrocolombiana, patrocinado por el Ministerio de Cultura de Colombia, del cual el autor hizo parte en la preparación, organización y estudio de las novelas del escritor Gregorio Sánchez Gómez.
} 
Cali, publicara varias de sus obras, aprovechando que era el mayor accionista en la primera editorial moderna que tuvo la ciudad de Cali en toda su historia, Editorial América.

El libro hizo parte de una serie de 6 novelas escritas y publicadas por editorial América entre 1930 y 1940 El Gavilán, Casada y sin marido, El hombre en la hamaca: divagaciones de un ocioso, El burgo de don Sebastián. A pesar de que la novela apareció anunciada desde 1940 en otro de los grandes libros de Gregorio Sánchez, Sociología política colombiana, fue dada a conocer al público por sus hermanos cinco años después de la muerte del escritor, en 1947.

Todavía son desconocidos los hechos que llevaron a Gregorio Sánchez, un abogado de profesión, a la población minera de Marmato. Información, no muy precisa, sugiere que Gregorio llegó a la zona en calidad de ingeniero de minas, otros sugieren que fue su nombramiento como director del periódico El impulso de Riosucio, lo que generó su traslado al departamento de Caldas; estos hechos continúan siendo investigados, igualmente, las razones que puedan explicar porque la obra escrita a finales de los años treinta y anunciada en 1940, solo se pudo publicar siete años después de su escritura, cuando otros libros escritos en la misma coyuntura salieron a la luz pública.

La novela la podemos dividir en dos partes. La primera parte, que transcurre a través de los tres primeros capítulos, nos presenta el Marmato de antes, es decir, un distrito minero ocupado por una serie de pequeños y medianos propietarios de minas, como Florencio Botero, uno de los personajes, que se encontraba explotando algunas minas de su propiedad. Esta primera parte termina con la llegada de un destacamento del ejército oficial al mando del general Mandíbula, que haciendo cumplir la ley desaloja a los propietarios mineros, experiencia en la que muere Florencio Botero, cuando un soldado cumpliendo la orden de desalojo le propina un disparo en presencia de su mujer Cecilia Barbosa y de su hija Donatila.

Este pasaje de la novela, sin lugar a dudas, hace alusión a unos de los hechos más importantes en la historia de Marmato. Estoy haciendo referencia a la ocupación llevada a cabo por Eduardo Vásquez Cobo en 1906, que como dice Otto Morales Benítez, fue una posesión violenta con pretensión de toda la región aurífera de Supía y Marmato.

Recordemos que Eduardo Vásquez era uno de los hermanos de Alfredo Vásquez Cobo, ministro de relaciones exteriores de Rafael Reyes y, lo que es más importante, arrendatario 
de una gran variedad de minas de Supía y Marmato. Estos privilegios los había obtenido Alfredo Vásquez como reconocimiento oficial a su abnegada participación en la guerra de los Mil días. Un año antes de la ocupación, en 1905, el ministro Vásquez había hecho traspaso de su contrato por veinte años a la The C. W. Sindicate Limited, negocio que le permitió a Vásquez Cobo asegurar unos honorarios importantes. De esta forma lo que aparece en la novela como la Concesión no fue otra cosa que la apropiación de los recursos mineros nacionales por parte de empresas transnacionales, haciendo uso de la fuerza, la violencia y con la complicidad de los funcionarios más prestantes del Estado colombiano. La segunda parte, del capítulo cuarto en adelante, el protagonismo lo tiene la empresa minera inglesa, única propietaria de las minas y con la libertad de explotar el oro a través de la tecnología de los molinos. La empresa, sus propietarios y los rasgos de una gran masa de trabajadores en los socavones son descritos en cada uno de los capítulos. Igualmente los empleados de la empresa que desempeñan una labor protagónica en la novela: un ingeniero, el administrador, el médico, un abogado y un contador. El día sábado en el caserío; el domingo día de mercado; el jolgorio de los negros y mulatos, el derrumbe y la muerte en las minas, el menosprecio por los gitanos y el conflicto de celos entre las mujeres que se disputan un barón, son, entre otros, los hechos de la vida diaria que constituyen el relato novelesco.

La obra termina cuando Aspasia muere quemada en un incendio que ella provocó para evitar que la pusieran presa por el rapto de la niña Mary; antes de morir se dolió de la muerte de su perro, Tigre, pero puso a salvo a Mary. El final de la novela puesto de esta forma nos pone de nuevo ante los comienzos de la misma. La muerte de ambos personajes Florencio Botero y Aspasia (Cecilia Barbosa), una niña en medio del peligro, violencia, destrucción, incendio y, lo que es más importante, la contradicción de los intereses de la empresa minera y el mundo de los trabajadores en los socavones.

Además de la descripción física de los caseríos de San Juan, Marmato, Salamina, Aguadas y Pácora, del Molino Santa Mónica, El molino Las vueltas, y La Pintada; las condiciones socioeconómicas de los peones y el despojo de las tierras a que eran sometidos, además de darnos a conocer el mapa sociocultural de las minas, Gregorio Sánchez logra, de manera perfecta, describir los rituales mágico religiosos de la población negra y mestiza que trabajaba en las minas. 
Dudo mucho que un sociólogo profesional hubiera podido reconstruir el mapa social desde una mina, o que un antropólogo hubiera podido dar cuenta a cabalidad de los rituales y de todas las expresiones simbólicas del conflicto, o que un historiador pudiera haber construido un relato acudiendo a las identidades socio-culturales y a las relaciones sociales. Gregorio Sánchez lo logra apelando a los recursos narrativos propios de la literatura, particularmente, a la ficción que le aporta la cultura africana y mestiza de Marmato.

\section{Istmina, Marmato y Cali: la construcción geográfica y simbólica de la novela}

Pero estas expresiones no eran nuevas en Gregorio Sánchez. En tres de sus novelas anteriores La piedad del mar, La envidia de los dioses y La flor del tabaco, todas escritas en 1924, había apelado a los diferentes aportes de la cultura oral negra para dar cuenta de la realidad social y sentimental de las poblaciones Chocoanas. Por lo tanto, no debe parecernos extraña la sensibilidad profunda de un hombre que nacido en una zona minera, como Istmina, en 1895, que igualmente a las zonas occidentales de Caldas, su población había sido explotada por compañías transnacionales americanas, con la complicidad de los diferentes gobiernos de turno.

Es en este sentido importante que conozcamos las relaciones históricas y socio económicas que el libro parece establecer a partir de las tres poblaciones: Istmina, lugar de nacimiento del autor; Marmato, espacio dónde se lleva a cabo la historia del relato y Cali como el lugar dónde se escribe y se publica el libro, lugar de residencia del autor y su familia.

Desde la época colonial Marmato hizo parte de la Unidad Político Administrativa de la gobernación de Popayán. Los expertos nos cuentan que desde el Siglo XVI se explotaban minas de filón en el Cerro de Marmato. De esta forma el territorio se integra al eje minero colonial integrado por Anserma, Arma y Supía, para luego articularse a Santafé de Antioquia.

Si bien es cierto que los habitantes nativos del territorio fueron los indios Cartama, desde el Siglo XVII un personaje como el capitán Jacinto Arboleda empleaba una cuadrilla de cuarenta esclavizados negros en la explotación de las minas de este territorio; para 1801 la región contaba con un número cercano a los quinientos esclavizados.

Después de la independencia (1835) San Juan de Marmato integraba el Cantón caucano de Supía con los territorios de Quiebralomo y Supía. Para 1857 San Juan de Marmato pasa a ser considerado Distrito Minero del Estado del Gran Cauca. Pero desde 1823 el Estado para

Poligramas 35, primer semestre 2011, ISSN 0120-4130. 
compensar los apoyos de los ingleses a la causa independentista, cedió sus territorios mineros en calidad de arrendamiento por veinte años a la empresa Goldschmith \& Co. de Londres, contrato que fue restituido continuamente hasta 1905.

Además de haber hecho parte de los grandes acontecimientos de la vida republicana de la nación, fue continuamente visitada por personajes como el profesor de Química y mineralogía J. B. Boussingault, y el ingeniero Moore. Boussingault y Moore igual que Walter, Nisser, Paschke, de Greiff y Johnson, aportaron la experiencia minera adquirida en Alemania; sus conocimientos científicos y tecnológicos, igualmente, fueron decisivos para el desarrollo minero de esta zona del país.

Otro de los personajes que llegó a Marmato en la Segunda mitad del Siglo XIX fue don Jorge Ricardo Isaacs. En medio del descontento de los conservadores y de cierto sector de la iglesia, la presencia del secretario de Instrucción pública que era el cargo que detentaba Jorge Isaacs al ser nombrado por su primo Cesar Conto, presidente del Gran Cauca llamó la atención de los habitantes de esta población minera del Cauca. Su padre, Jorge Enrique, había llegado de Jamaica en busca de oro a otra de las regiones mineras del Cauca, el Chocó. De ahí en adelante las correrías y aventuras empresariales y políticas de los IsaacsFerrer empezaron a conectar la frontera minera del Chocó con la región plana del valle geográfico del Rio Cauca, particularmente, la zona de Cali, Palmira y Cerrito. Cerca de medio siglo después de la llegada de su padre, Jorge Ricardo se dirigió a conocer a San Juan de Marmato, quizás el Distrito más importante que tenía el Cauca en materia minera. Las primeras décadas del Siglo XX continuaron marcadas por las problemáticas de orden nacional. Las disputas de los Vásquez Cobo por los territorios mineros, los intereses del presidente Reyes y la continuidad de las empresas mineras trasnacionales tuvieron un solo nombre, el oro. Para 1910 se crea el Departamento de Caldas con Manizales como capital, y el Distrito minero de Marmato pasa del gobierno de Popayán a la tutela de una nueva administración política en medio de la corrupción, el desalojo, la violencia y el movimiento de sectores importantes de la población que intentaban resistir y defender sus intereses.

Creo que estos hechos fueron suficientes para llamar la atención de un escritor como Gregorio Sánchez. Pero tampoco sobra decir que el hecho de haber nacido en el Chocó una de las tres zonas mineras más importantes del Cauca, las otras eran, según Vicente Restrepo, Barbacoas y Supía generó una serie de coincidencias y de procesos que con el

Poligramas 35, primer semestre 2011, ISSN 0120-4130. 
tiempo se convirtieron en verdaderos antecedentes e insumos para la escritura de su novela, La bruja de las minas.

Istmina, fundada por Juan Nepomuceno Mosquera (1834) inicialmente reconocida como Partido del Cantón de San Pablo, hizo parte de la Provincia de San Juan, una de las fronteras mineras que, conjuntamente con el Atrato, se convirtieron en asiento de esclavizados, mineros y comerciantes que poco a poco se instalaron en un sin número de caseríos y le dieron forma a una incipiente vida comercial al calor de la explotación aurífera. Los ricos hacendados, mineros y comerciantes de Cali llegaron a ser propietarios de reales de minas en esta frontera como en el Raposo. En el Siglo XVIII lograron estructurar unidades de producción, es decir las haciendas, para complacer la creciente demanda de alimentos por parte de los yacimientos mineros. Fue de esta forma como se empezaron a definir los lazos que desde temprano articularon a Santiago de Cali con estas regiones mineras del pacífico.

Igualmente a Marmato, la Provincia de San Juan estuvo inicialmente bajo la tutela de la gobernación de Popayán y, para el Siglo XIX, el Distrito de San Pablo (Municipio de San Juan) hacía parte de la Unidad PolíticoAdministrativa del Gran Cauca. Hacia 1884 San Pablo era reconocido, simultáneamente, con Novita, Tadó, Condoto, Sipí y Cajón, como uno de los principales pueblos productores de oro del municipio de San Juan; los otros pueblos como Quibdó, Bagadó Lloró, Neguá y Bebará pertenecían al municipio del Atrato. Es en este ambiente de explotación del oro a través del mazamorreo y de intensa actividad comercial para proveer la creciente demanda de los diferentes distritos mineros, nace Gregorio Sánchez padre y nuestro escritor Gregorio Sánchez Gómez.

Iniciando el Siglo XX Istmina aparece como municipio y capital de la Provincia de San Juan. Para 1908, bajo la presidencia de Rafael Reyes, se crea el Departamento del Chocó con Quibdó como capital e Istmina pasa a ser reconocida como municipio y deja de ser llamada San Pablo. Pero, dos años después, la nación crea diez departamentos, entre ellos Manizales y el Valle del Cauca, y el Chocó pasa a ser una simple Intendencia bajo la administración nacional.

De igual forma como las empresas mineras inglesas y norteamericanas establecieron sus intereses estratégicos en el territorio de Marmato, los distritos mineros de las diferentes zonas del Pacífico caucano vieron entrar las dragas extranjeras y apropiarse de los recursos

Poligramas 35, primer semestre 2011, ISSN 0120-4130. 
mineros bajo la anuencia de la clase dirigente nacional y regional. La compañía Minera Chocó Pacífico constituyó una clara expresión de esta realidad desde finales del Siglo XIX como bien lo enseña un investigador como Aquiles Escalante, y la The Nem. Timbiquí Gold Mines, Ltda. a comienzos de Siglo XX. Un destacado parlamentario liberal, como Sofonias Yacup, realizó ingentes esfuerzos y encabezó un movimiento en contra de las trasnacionales que explotaban los recursos auríferos de su tierra natal. En su libro, Litoral recóndito, libro poco leído y citado, dejó descrito los pormenores llevados a cabo para defender los intereses nacionales.

Pero esta realidad era solamente una expresión de un contexto mucho más complejo. Entre finales del Siglo XIX y Las primeras décadas del Siglo XX la penetración del capital trasnacional no solo expresó sus intereses en la riqueza aurífera nacional, como bien lo documenta el profesor Fred J. Rippy, después de la pérdida de Panamá el petróleo, el banano y los préstamos directos, también, fueron objeto de las ambiciones del capital norteamericano.

Pese a que colombianos como Gregorio Sánchez, nacieron hacia finales del Siglo XIX en caseríos, distritos y poblados y luego se encontraron para la segunda década del Siglo XX con nuevas unidades político administrativas, como el Departamento del Valle del Cauca y Caldas, sus diversas actividades no abandonaron las tradicionales relaciones y articulaciones espaciales. Fue así como Santiago de Cali, capital del Departamento del Valle del Cauca para 1910, continuó siendo el espacio de recepción de las personas nacidas en el pacífico o en tránsito hacia él. Detrás de los Isaacs-Ferrer y los Sánchez-Gómez prosiguieron las oleadas de nativos del pacífico, que una y otra vez en su tránsito legitimaron la hermandad entre estas dos regiones del territorio nacional. Lo curioso dada la temprana influencia de Santafé de Antioquia y Medellín sobre Marmato es constatar una oleada migratoria de marmateños hacia la ciudad de Cali, que hacia mediados del Siglo XX llevados por las minas de carbón en la zona de ladera pueblan y fundan uno de los más populosos barrios de Cali, Siloé.

\section{La modernización y la modernidad cultural en la novelística de Gregorio Sánchez}

Para aquellos que hemos sido educados en la creencia de que la violencia Colombiana fue una confrontación de partidos políticos iniciada con la muerte de Jorge Eliécer Gaitán, en 
La bruja de las minas encontramos no solo la explotación y el saqueo de los recursos mineros naturales por empresas transnacionales americanas, sino la explotación, el asesinato y, en general, la violencia para la década de los años treinta.

Los conflictos, la violencia social colombiana y los valores decadentes fueron temas predilectos de su obra. En este sentido, sus novelas de amor, y casi siempre definidas en torno al destino trágico pusieron al descubierto, las temáticas más vedadas para la sociedad de ese entonces.

Su mirada sociológica, la sensibilidad especial que tuvo siempre para representar los sentimientos y la cultura, y su coherencia para dar cuenta de los conflictos sociales, temas que ya se habían asumido en otras de sus obras, quedaron magistralmente plasmadas en esta novela. El trabajo en las minas, los aspectos sociales de los caseríos, la violencia y, particularmente, el despojo y los asesinatos, el cuerpo, el color de la piel, la pobreza, las expresiones orales negras y populares, el mapa social de las minas y el destino, son algunos de los temas representados por Gregorio Sánchez en esta obra

Pero lo que más emociona es la forma como quedó concebido el conflicto social en la novela: De un lado están "los gringos" y su administrador, el contador y el médico como Gregorio Sánchez llama a los propietarios de la compañía y el capital, representados en personajes como Mister Stanley, John Morris, Henry Lawrence, Peter Simon. Del otro están los peones, las cuadrillas de mineros y las brigadas obreras representados en personajes populares y cotidianos como Sabina Pérez, la cocinera, Felisa Barco, Roque Montoya, Joel Agudelo, Jacinta, Serafina (la Tolimense), Engracia Buritica, Florencio Botero, Cecilia Barbosa, Donatila, Zacarías Euse, Aspasia, La Pascuala, Petra Cañizo, Gutiérrez, el alcalde "pío quinto” y el general Mandíbula. Este espacio social que uno puede simplificar en el mundo de la Compañía, de un lado, y el mundo de Aspasia, del otro, sus múltiples representaciones del conflicto, expresadas en los límites y las fronteras sociales, en las identidades individuales y de grupo, en las resistencias, en las disposiciones mentales de los personajes y, particularmente, en sus sentimientos, quedaron plasmados tanto en la trama particular de la novela, como en las descripciones y juicios de valor particulares del narrador.

Pero al interior de cada uno de estos grupos sociales en que están expresado las relaciones de subordinación y la lucha, también, presentan conflictos, tensiones e intereses; la cortada 
que propina la Lola en la cara de Engracia puede ser un buen ejemplo de ello. Es decir, no es solamente las relaciones de subordinación y de lucha de clases lo que define la situación de los personajes en la novela, las pasiones, las venganzas, los amores y las traiciones, también, logran definirlos

Quizás uno de los aspectos claves a considerar, en el esfuerzo que se le reconoce a Gregorio Sánchez por hacer una sociología de un país como Colombia, poniendo a la luz personajes cotidianos, populares y anónimos frecuentemente invisibilizados por el poder es la forma como logra individualizar, objetivar, construir identidades y percepciones diferenciadas en el espacio social. En este sentido, la mediación étnica africana popular y sus múltiples imágenes, la participación de las mujeres, la muerte, la desnudes y el movimiento del cuerpo, son recursos, que además de darle fuerza al relato, logran poner en evidencia las lógicas del poder, el orden social y la violencia.

Las diferencias, yuxtaposiciones y contradicciones socioculturales de un país como Colombia quedaron plasmadas en la estructura del relato. El trabajo de diferentes profesionales, el uso de tecnologías como los Molinos para la explotación minera, la oficina de Ensayo, el depósito de cianuro y ciertas prácticas disciplinarias sobre empleados y trabajadores le daban a la empresa minera un aire de organización moderna, que contrastaba con la vida miserable de cientos de mineros que laboraban en los socavones, con ciertas formas laborales practicadas por la empresa, como el sistema de pagos con bonos, la corrupción, la violencia y la muerte.

Igualmente, los esfuerzos inútiles de un médico como Mister Stanley, que luchan por medicar los cuerpos y aplicar conocimientos médicos para dar cuenta de la enfermedad de los sectores populares negros y mestizos, mientras éstos los resisten y rechazan porque creen en los hechizos, los brebajes y las brujerías. Es decir, creen más en la bruja de las minas para solucionar sus dolencias y problemas de amor, que en el médico que les ofrece la empresa. Brebajes, brujería, hechicería en un mundo dónde la religión católica no se le percibe presencia, solamente las vírgenes son de vez en cuando nombradas.

La participación de Gregorio en la "novela semanal" logro acercarlo a escritores y escritoras que conformaban un grupo muy particular en el campo intelectual colombiano, estoy haciendo referencia a Emilio Cuervo Márquez, Simón Latino, Rafael María 
Rodríguez, Bernardo Arias Trujillo, José María Rivas Groot, Uva Jaramillo, Cruz Alba, José Asunción Silva, José Eustasio Rivera y León de Greiff entre otros.

Los editores del libro aprovecharon las solapas del mismo para dar a conocer diferentes opiniones de los escritores anteriores, así como de reconocidos intelectuales extranjeros, sobre nuestro escritor. Por ejemplo, la opinión de un reconocido intelectual de la época como el escritor Antonio Gómez Restrepo quedó expresada en los siguientes términos:

Sánchez Gómez tiene el arte del novelista no solo en la concepción de sus obras, sino en la manera de introducir sus personajes y de presentar sus episodios. Y en el estilo sencillo, vigoroso y pintoresco, poético cuando se ofrece, pero estilo de narrador, no de poeta en prosa.

También apelaron al reconocimiento del académico Español Ángel Dotor y Municio, autor de numerosos libros, quién logra exaltar las virtudes de Sánchez en el contexto relacional de la figura de Jorge Isaac y José Eustasio Rivera. El crítico Español sostuvo:

Colombia que otrora produjo un Isaacs, narrador consustantivo con su espíritu vernáculo como pocos, y que recientemente contó con el malogrado José Eustasio Rivera otro gran plasmador del alma de las selvas inmensas, tiene hoy en Sánchez Gómez el gran narrador sincrético, cuya labor denota rotundamente el medio en que se ha producido y la alta ley intelectual de su autor.

Aproximadamente diez años después de la publicación del libro, los editores compilan un conjunto de opiniones de reconocidos escritores y periodistas, tanto nacionales, locales y extranjeros, sobre la obra de Gregorio Sánchez. De La bruja de las minas conceptuaron de la siguiente manera:

La bruja de las minas es relato de minería, tremendo, doloroso, por donde cruzan vidas de hombres desalmados, intrigantes, ladrones, asesinos, trabajadores que cambian a veces el jornal por licor, por amor o por dolor. En todo el libro hay vida, pero no de la burguesa, la que palpita falsificada bajo trajes de etiqueta, sino vida más cruda, dura, la de gentes que viven al natural. Justicias e injusticias, explotaciones y luchas, lo que sufren seres de carne y hueso, no muñecos salidos de la imaginación del autor. En esta obra se hallan las mejores virtudes de Sánchez Gómez como narrador, como pintor verídico y fuerte de costumbres. Es una especie de Efe Gómez vallecaucano, en la colada reciedumbre del estilo y en los agudos atisbos sicológicos.

Poligramas 35, primer semestre 2011, ISSN 0120-4130. 
“José Gers” (José Gerardo Ramírez Serna) Cronista colombiano. En el Relator, de Cali. Una segunda opinión fue descrita en los siguientes términos:

La bruja de las minas está escrita en estilo vibrante, suelto y ágil, castizo y fluido, que poco a poco va cautivando el interés del lector, mientras le embebe los ojos, dibujándoselo, con la descripción magistral del paisaje duro y quebrado de la región minera caldense; con la pintura realista de personajes dignos del medio y con el aporte del espíritu novelesco esencial a toda obra de tal índole.

Llena la novela de un sentido de lucha, de un erguido ánimo, tal vez de orientación política que apenas se insinúa, pero de sólido fondo trágico, bien puede ocurrir que ella no esté destinada a la masa por ser, realmente, una diatriba de la violencia. Es obvio que esta nueva novela de Sánchez Gómez no va a gustar a todos. Ella no resuelve cuestiones políticas, que no por largas y duraderas dejan de ser transitorias. Va a estratos más hondos de la personalidad humana y de la lucha por la vida. Va hacia la cima de la existencia.

"JEQ" (Jesús Elias Quijano)

Periodista colombiano. En Suplemento Literario de El tiempo de Bogotá.

Una tercera opinión no deja de percibir en la obra aspectos claves que son registrados en el orden de la denuncia política, e igualmente el enunciado propone el diálogo de la novela con otros autores y otras obras:

La desvertebrada y abrupta geografía de Marmato sirve de fondo a la nueva narración de Sánchez Gómez, La bruja de las minas, donde como en un film profundamente humano, aparecen en escena los eternos protagonistas de nuestras minas. No faltan allí los agentes de los capitales extranjeros que con el acerado ritmo de las máquinas extraen el rubio metal de las entrañas oscuras de la tierra. Ni los simulacros de autoridades que desempeñan el papel de sirvientes a sueldo del imperialismo, con mengua del sentimiento nacionalista. Ni el dolor sin nombre de la negredumbre irredenta que se ahoga y se asfixia en los antros dantescos. Ni los días caliginosos de enervante faena que se traducen en cheques para los capataces, en cansancio y fiebre para los músculos de ébano, en cálculos y alegrías para los aventureros. Tampoco faltan las noches de jolgorio, estremecidas de vértigos sensuales y acompasadas de currulaos y de cumbias. 
Sánchez Gómez es fiel intérprete de la realidad circundante. Sus personajes son de carne y hueso. Se los encuentra en Marmato, en Barbacoas, en el Chocó. En su obra hay capítulos que recuerdan la garra de acero de Arias Trujillo en los mejores párrafos de Risaralda. No hay en este libro mistificaciones sicológicas. Alientan en él enunciados sociales en trance de discusión continental, exaltaciones de la vida frente a los avatares económicos de un conglomerado. De este modo, el nuevo libro de Sánchez Gómez se orienta hacia los modernos horizontes estéticos.

De El radio de Pasto.

Pese a que la novela no ha sido registrada en las clasificaciones de los manuales oficiales, su reedición tiene como objetivo el reconocimiento, debe ser reconocida como lo fueron varias de las novelas escritas en la república liberal de los años treinta. Estoy haciendo referencia a obras como El estudiante de la mesa redonda (1932) de Germán Arciniegas, Cuatro años a bordo de mí mismo (1934) por Jorge Zalamea Borda, La cosecha (1935) de José Antonio Osorio Lizarazo, Mancha de aceite (1935) por el médico César Uribe Piedrahita, Risaralda (1935) de Bernardo Arias Trujillo y Una derrota sin batalla (1935) de Luis Tablanca, entre otras.

Gregorio Sánchez murió en diciembre de 1942 cuando desempeñaba el cargo de bibliotecario en la biblioteca municipal de Cali, contando apenas con cuarenta y siete años, algo parecido ocurrió con uno de los escritores colombianos y amigo de Gregorio, Bernardo Arias Trujillo. Bernardo, autor de Risaralda y de muchos otros textos desconocidos por los colombianos, murió cuando tenía treinta y cinco años de edad.

A pesar de su gran producción literaria, de haber ejercido cargos estatales a nivel local, de haber dirigido periódicos como El impulso en Rio Sucio, de haber sido referenciado por un puñado de escritores de su época y algunos críticos literarios, de Gregorio Sánchez Gómez 'nadie sabe nada'; nadie se acuerda de él; nadie tiene referencias, ni Chocoanos, ni Vallunos, ni Caleños, ni marmateños y tan solo como rastro suyo, solo quedan, de sus veinte obras publicadas, nueve libros en la 'Sala Valle' del actual Centro Cultural Rodrigo Lloreda; igual número de libros en el Instituto Caro y Cuervo; un ensayo, Fémina: Reflexiones sobre la mujer y su destino, en la Biblioteca de la Universidad San Buenaventura; y la obra casi completa en la Biblioteca Luis Ángel Arango de Bogotá. Ninguno de estos espacios posee una conciencia real del valor de esta obra. 
Por eso la recuperación que estamos realizando a través de esta reedición es todo un acontecimiento. Aunque las obras habían empezado a ser reeditadas por los hermanos y su padre en 1958, al reeditar en un solo libro Novelas cortas las novelas que habían sido publicadas en la Revista semanal de Luis Enrique Osorio en 1924. Práctica de recuperación y reedición continuada por la Universidad del Valle en 2004, cuando en su Décima Feria del libro lanzó la primera reedición de La bruja de la minas.

Desconocemos si Gregorio leyó un libro como Litoral recóndito escrito en 1934, por Sofonías Yacup, un parlamentario liberal guapireño muy conocido en el medio político. Igualmente si coterráneos suyos como Diego Luis Córdoba, Rogerio Velásquez Murillo, Neftalí Mosquera Mosquera, Miguel Ángel Caicedo Mena y Arnoldo Palacios, o Manuel y Juan Zapata Olivella, Jorge Artel tuvieron acceso a su obra. No sabemos si se conocieron, si se leyeron o departieron, pero ello no es un obstáculo para construir una línea de análisis que valla de unos a otros, configurando de esta forma un campo de interpretaciones en el tiempo que logre objetivar percepciones, clasificaciones y objetivaciones de los intelectuales que hoy estamos denominando Afro colombianos.

Somos conscientes que aún falta mucho por investigar sobre los pormenores que dieron origen tanto a la escritura de la novela, como a la producción del libro. Sin embargo, estamos seguros de estar realizando un aporte al rescatar un escritor que ha sido

invisibilizado, poco leído, estudiado, comentado e ignorado por las clasificaciones y objetivaciones de la nueva y vieja academia.

\section{Bibliografía:}

Sánchez Gómez, Gregorio. La Bruja de las Minas. Cali: Editorial América, 1947.

La Bruja de las Minas. Cali, Programa Editorial Universidad del Valle, 2004.

Sánchez Gómez, Gregorio. Algunos conceptos sobre sus obras. Bogotá, Sánchez Gómez Eduardo, 1958

Yacup, Sofonías. Litoral recóndito. Bogotá: Editorial Reconocimiento, 1934.

Díaz López, Zamira. Oro, sociedad y economía. El sistema colonial en la gobernación de Popayán: 1533-1733. Santafé de Bogotá: Banco de la República, 1994.

West, Robert C. La minería de aluvión en Colombia durante el periodo colonial. Bogotá: Imprenta Nacional, 1972. 
Escalante Polo, Aquiles. La minería del hambre. Condoto y la Chocó pacífico. Ediciones Universidad de Medellín, Córdoba y Simón Bolívar. 1971.

Restrepo, Vicente. Estudio sobre las minas de oro y plata de Colombia. Bogotá: Banco de la República, 1952.

Ramos, B. Juan Diego. Oro. Un recorrido por la tecnología minera de Antioquia. Medellín: Universidad de EAFIT, 2007.

El Chocó ayer y hoy. Publicaciones de la Secretaría de Gobierno, Imprenta Oficial, 1936.

González Escobar, Luis Fernando. Quibdó. Contexto histórico, Desarrollo urbano y patrimonio arquitectónico. Medellín: Centro de Publicaciones Universidad Nacional de Colombia-Medellín, 2003.

Rippy, Fred J. El capital norteamericano y la penetración imperialista de Colombia. Bogotá: Editorial La Oveja Negra, 1970. 